NASA/TM-2003-212878

\title{
Computation of Transverse Injection Into Supersonic Crossflow With Various Injector Orifice Geometries
}

Lancert E. Foster

Glenn Research Center, Cleveland, Ohio

William A. Engblom

The Aerospace Corporation, Cleveland, Ohio 
Since its founding, NASA has been dedicated to the advancement of aeronautics and space science. The NASA Scientific and Technical Information (STI) Program Office plays a key part in helping NASA maintain this important role.

The NASA STI Program Office is operated by Langley Research Center, the Lead Center for NASA's scientific and technical information. The NASA STI Program Office provides access to the NASA STI Database, the largest collection of aeronautical and space science STI in the world. The Program Office is also NASA's institutional mechanism for disseminating the results of its research and development activities. These results are published by NASA in the NASA STI Report Series, which includes the following report types:

- TECHNICAL PUBLICATION. Reports of completed research or a major significant phase of research that present the results of NASA programs and include extensive data or theoretical analysis. Includes compilations of significant scientific and technical data and information deemed to be of continuing reference value. NASA's counterpart of peerreviewed formal professional papers but has less stringent limitations on manuscript length and extent of graphic presentations.

- TECHNICAL MEMORANDUM. Scientific and technical findings that are preliminary or of specialized interest, e.g., quick release reports, working papers, and bibliographies that contain minimal annotation. Does not contain extensive analysis.

- CONTRACTOR REPORT. Scientific and technical findings by NASA-sponsored contractors and grantees.
- CONFERENCE PUBLICATION. Collected papers from scientific and technical conferences, symposia, seminars, or other meetings sponsored or cosponsored by NASA.

- SPECIAL PUBLICATION. Scientific, technical, or historical information from NASA programs, projects, and missions, often concerned with subjects having substantial public interest.

- TECHNICAL TRANSLATION. Englishlanguage translations of foreign scientific and technical material pertinent to NASA's mission.

Specialized services that complement the STI Program Office's diverse offerings include creating custom thesauri, building customized databases, organizing and publishing research results ... even providing videos.

For more information about the NASA STI Program Office, see the following:

- Access the NASA STI Program Home Page at http://www.sti.nasa.gov

- E-mail your question via the Internet to help@sti.nasa.gov

- Fax your question to the NASA Access Help Desk at 301-621-0134

- Telephone the NASA Access Help Desk at 301-621-0390

- Write to:

NASA Access Help Desk

NASA Center for AeroSpace Information 7121 Standard Drive

Hanover, MD 21076 
NASA/TM-2003-212878

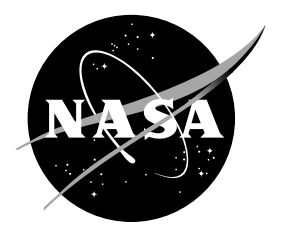

\section{Computation of Transverse Injection Into Supersonic Crossflow With Various Injector Orifice Geometries}

Lancert E. Foster

Glenn Research Center, Cleveland, Ohio

William A. Engblom

The Aerospace Corporation, Cleveland, Ohio

Prepared for the 42nd Aerospace Sciences Meeting and Exhibit sponsored by the American Institute of Aeronautics and Astronautics Reno, Nevada, January 5-8, 2004

National Aeronautics and

Space Administration

Glenn Research Center 


\section{Acknowledgments}

The authors would like to thank Dr. Rickey Shyne, Dr. Nicholas Georgiadis, Dr. James Debonis, and Mr. Dennis Yoder, NASA GRC, for technical contributions.

This report is a formal draft or working

paper, intended to solicit comments and ideas from a technical peer group.

This report contains preliminary

findings, subject to revision as analysis proceeds.

Trade names or manufacturers' names are used in this report for identification only. This usage does not constitute an official endorsement, either expressed or implied, by the National Aeronautics and Space Administration.

This report is a preprint of a paper intended for presentation at a conference. Because of changes that may be made before formal publication, this preprint is made available with the understanding that it will not be cited or reproduced without the permission of the author.

This work was sponsored by the Low Emissions Alternative

Power Project of the Vehicle Systems Program at the NASA Glenn Research Center.

Available from

NASA Center for Aerospace Information 7121 Standard Drive

Hanover, MD 21076
National Technical Information Service 5285 Port Royal Road Springfield, VA 22100 


\title{
COMPUTATION OF TRANSVERSE INJECTION INTO SUPERSONIC CROSSFLOW WITH VARIOUS INJECTOR ORIFICE GEOMETRIES
}

\author{
Lancert E. Foster* \\ National Aeronautics and Space Administration \\ Glenn Research Center \\ Cleveland, Ohio 44135 \\ William A. Engblom ${ }^{\dagger}$ \\ The Aerospace Corporation \\ Cleveland, Ohio 44135
}

\begin{abstract}
Computational results are presented for the performance and flow behavior of various injector geometries employed in transverse injection into a nonreacting Mach 1.2 flow. 3-D Reynolds-Averaged Navier Stokes (RANS) results are obtained for the various injector geometries using the Wind code with the Mentor's Shear Stress Transport turbulence model in both single and multi-species modes. Computed results for the injector mixing, penetration, and induced wall forces are presented. In the case of rectangular injectors, those longer in the direction of the freestream flow are predicted to generate the most mixing and penetration of the injector flow into the primary stream. These injectors are also predicted to provide the largest discharge coefficients and induced wall forces. Minor performance differences are indicated among diamond, circle, and square orifices. Grid sensitivity study results are presented which indicate consistent qualitative trends in the injector performance comparisons with increasing grid fineness.
\end{abstract}

\section{INTRODUCTION}

\section{Motivation}

Fluid injection into a supersonic crossflow has recently been a focus of investigations for application to ramjet/scramjet combustion. Quick penetration and mixing of injection fluid are metrics of interest here due to the short combustor residence times involved.

There is also significant interest in the applications, albeit with lower speed supersonic crossflows $(\mathrm{M}<2)$, to jet engine noise damping and thrust-vectoring. The interest in noise damping stems from the success of chevron nozzles, which have been shown to significantly reduce jet engine noise levels. Apparently, the large-scale streamwise vortices created by the chevroned-nozzle geometry induce jet exhaustfreestream mixing, which promotes noise reduction. It is thought that creating strong streamwise vortical structures (and the resulting increased mixing) via transverse injection near the trailing edge of a nozzle could promote noise reduction in an analogous manner.
The application to thrust-vectoring within a nozzle by using an injected flow to induce a wall force is also of interest relative to improving nozzle performance or vehicle stability and control.

Clearly, it is important to obtain a qualitative understanding of how the aforementioned performance characteristics (i.e., penetration, mixing, and induced wall force) are affected by injector configuration parameters. There are a wide variety of possible injector configurations including variations in orifice geometry, orientation relative to the primary flow, injector-to-freestream pressure ratios, etc.

\section{Literature Survey}

Tomioka, et al. [1], have experimentally investigated the sensitivity of penetration and mixing to injector configuration for a Mach 3 crossflow. The parametric study observed the effects of variations in jet-tofreestream dynamic pressure ratio, injector orifice shape, and injection angle. They noted better penetration for diamond-shaped orifice injectors versus equivalent area, circular orifice injectors. At large jetto-freestream dynamic pressure ratios, the plume penetration of the diamond-shaped injector is comparable to that of the circular injector.

Santiago and Dutton [2] experimentally studied the streamwise counter-rotating crossflow vortices generated during transverse injection into a supersonic crossflow. They assert that these vortices are the primary source of entrainment of crossflow mass into the injected fluid jet plume. Ben-Yakar et al. [3] found similar flow phenomena (e.g., counter-rotating vortices) for subsonic injection.

\section{Research Objectives}

The present study is focused on understanding the effects of variations of orifice geometry on the performance of flush-mounted injectors for a low supersonic flow $($ Mach $=1.2$ ). The performance criteria were penetration, mixing, and induced wall forces. The injector-to-freestream static pressure ratio is roughly 2:1. A numerical methodology is also developed to 
provide a reasonably efficient and fair comparison of injector performance among the various candidate orifice shapes. Note that experimental validation of the numerical findings is not available at the present time.

\section{METHODOLOGY}

\section{Model Geometry}

The model geometry (Fig. 1) consists of a Mach 1.2 primary stream duct flow, and a subsonic ( Mach 0.3) secondary injector flow. The injector domains are connected to the duct bottom wall, and have uniform cross-sectional area (as shown). The duct domain is an 8 by 8 in. cross-section, which extends for 96 in. All orifice geometry areas are $8 \mathrm{in}^{2}$. The choice of the relative size of the injector areas to duct width is arbitrary. Note that the sidewalls model neighboring rows of injectors (i.e., mirror images). The injector orifice geometries, depicted in Fig. 2, include circular, square, diamond, and eight slots with different lengthto-width $(\mathrm{L} / \mathrm{W})$ aspect ratios. For example, the 1:8 slot (or latitudinal slot) is 1 by 8 in., and oriented across the entire width of duct, while the 8:1 slot (or longitudinal slot) is 8 by 1 in., and oriented along the duct length.

\section{Grid Resolution}

The duct grid is configured to provide the fairest comparison among the injectors. Since the injector jet shear layers are 3-D and curved in nature, it is not possible to construct one duct grid to finely resolve these features for each injector case, without an extremely large grid. Consequently, the duct portion of each grid has near uniform spatial resolution in the injector near-field region, and is identical for each injector case. It is thought that by employing a nearly Cartesian mesh that the development of the turbulent flowfield will not be biased towards a given injector configuration.

The injector grids also have nearly consistent spatial resolution in all directions, regardless of geometry (e.g., each injector face consists of nearly the same number of cells. The grid for each injector is "attached" to the main duct grid via a mismatched cell face boundary. The turbulent boundary layers along the duct and injector walls are not resolved in an effort to maintain the near-Cartesian look of the grid. This is also done because the primary region of mixing is thought to be due more to interaction between the injection jet and primary stream, as opposed to driven by boundary layer effects.

Using the sequencing feature of the Wind code, a grid refinement study was performed (discussed in Results) to verify the consistency of the results. The grids could be sequenced from coarse to medium to fine with a factor of 8 increase in cells (i.e., x2 along I-, J-, and $\mathrm{K}$ - directions) between each level. Each grid consisted of approximately 600,000 points at the finest level.

\section{Flow Solver}

The flow solver chosen for this study was Wind (version 4), which is a merger of three older codes: NAST3D [4], NPARC [5], and NXAIR. Wind is a product of the NPARC alliance, a partnership between the NASA Glenn Research Center and the USAF Arnold Engineering Development Center (AEDC) dedicated to the establishment of a national, applications-oriented flow simulation capability. Wind is a node-based, finite-volume, multi-block structured code currently administered by AEDC. It permits mismatched zonal boundaries, grid sequencing, parallel-processing, and multi-species computation, all of which are necessary features for the present study.

A true second-order, spatially accurate (i.e., cell stretching is included) numerical scheme is implemented to solve the 3-D Reynolds-Averaged Navier-Stokes (RANS) equations. The inviscid fluxes were computed with Roe flux-difference splitting plus limiters to ensure monotonicity in the solution (i.e., to satisfy the TVD property). An implicit, 3-D spatial factorization scheme, with local time stepping, was chosen to drive the solutions to steady state. Mentor's [6] Shear Stress Transport (SST) model was chosen to handle the fine-scale turbulence effects; this model is a blended combination of $\kappa-\omega$ (near walls) and $\kappa-\varepsilon$ (away from walls).

\section{Numerical Assumptions}

An initial set of runs was conducted using a nonreacting 5-species air model. A frozen $\mathrm{M}=1.2$ condition was applied at the mainstream duct inflow plane, containing pure $\mathrm{N}_{2}$. A frozen $\mathrm{M}=0.3$ condition was applied at the injector inflow plane, containing pure $\mathrm{O}_{2}$. These multi-species mode runs insured constant injector mass flow (recall all injector face areas are constant), for the sake of comparison between the candidate injectors. Observation and identification of the mixing characteristics of the various injector configurations was the main goal of this portion of the study. Thus, the intent of this portion of the study was to determine which configurations generated more favorable mixing characteristics, given a constant injectant mass flow. An inviscid wall condition was applied at the sidewalls of each of the duct grids (to enforce the symmetry of a row of injectors). The flow conditions at the outflow boundary were extrapolated.

In a second set of runs for each injector, constant stagnation conditions were applied at the injector inflow plane. Riemann invariants (one-dimensional) 
were used to calculate the inflow and outflow conditions of the freestream. For these runs, a singlespecies air model was used and effective discharge coefficients and induced wall forces were obtained for the injector geometries. Table 1 summarizes the applied flow conditions.

\section{RESULTS}

\section{Primary Injector Geometries}

The "primary" set of injector geometries simulated includes the circular, diamond, square, and latitudinal slot injectors. In each case the massflow through the injectors is constant, as explained earlier. The first three cases exhibit similar mixing patterns and levels, and are distinctly different from the slot result. Figure 3 displays an injected mass fraction contour plot for the circular injector case, showing the flowfield along a planar cut through the center of the injector (mainstream flow is from left to right). In Fig. 4, a mass fraction contour plot is displayed for the same view with the latitudinal slot injector. The slot injector fluid does not penetrate well, compared to the circular injector. Figure 5 displays injected fluid mass fraction contour plots for the circular, diamond, square, and latitudinal slot injector cases at a plane $50 \mathrm{in}$. downstream of the center of the injector. The counterrotating streamwise vortices carry and mix the injector fluid well into the duct flow, causing the increased penetration. Interestingly, the diamond injector case results in the most complete propulsion of injectant into the primary stream, leaving no fluid along the duct floor. This more thorough clearing of injected fluid also occurs within a shorter distance downstream of the injector. Although the diamond injector produces a jet that seems to penetrate more quickly, it cannot be verified that better mixing is generated.

A bar chart comparison for the mixing creating by each injector is provided in Fig. 6. This "mixing metric" is defined herein as the percentage of the primary stream flow that contains at least 1 percent injector fluid, along a transverse cut 50 in. downstream from injector. Note that Fig. 5 illustrates the cuts from which this metric is calculated. This metric should be viewed as a qualitative indicator of the relative mixing induced by each injector. By this measure, the circular, diamond, and square injectors produce very similar levels of mixing, while the latitudinal slot produces significantly less. It is to be noted that latitudinal slot injectors are often cited as advantageous for flame-holding capability-the current non-reacting simulations cannot assess such capabilities.
The penetration generated by each injector was measured using the centroid of injected fluid at various downstream positions, following the method proposed by Barber et al. [7]. For each constant $x$ plane, fluid with an injectant concentration above 1 percent was summed to calculate the height of the centroid of injected fluid. This centroid penetration is plotted against downstream position in Fig. 7. The diamond injector consistently displays a slight advantage in centroid penetration, followed closely by the circular and then square injectors; this trend seems to be consistent with the injectant contour plots of the primary shapes (see Fig. 5). The latitudinal slot produces less than half the centroid penetration of any of the other three injector geometries.

\section{Rectangular Slot Aspect Ratio Study}

The next set of injector geometries simulated involves rectangular orifice shapes with varying aspect ratios (length/width). Including the latitudinal slot result, there are eight rectangular slot cases. Figure 8 displays injected fluid mass fraction contour plots for the rectangular injector cases at a plane 50 in. downstream of the center of the injector. The contour plots show improved penetration with increasing aspect ratio. Also, the plume appears to spread more, exposing more injected fluid to the freestream, allowing a greater opportunity for mixing. Both of these assertions are supported by the quantitative data. As with the primary geometries, the centroid penetration of the injected fluid was measured for each injector and plotted in Fig. 9. The injectant plume area of each case was calculated (using all area with at least 1 percent injectant) and plotted in Fig. 10. Clearly, injectant penetration and plume spreading increase directly with aspect ratio (length downstream).

The improved penetration is apparently largely due to a sustained generation of streamwise vorticity over a relatively long streamwise length. And this improved vorticity production is likely attributed to a "buffering effect." Specifically, the injector flow closer to the trailing edge of a longitudinal rectangular injector is better buffered from the axial momentum of the freestream by the streamwise vorticities developing along the forward portion of the injector. In addition, injected flow closer to the leading edge is given some upward lift from the trailing edge injector flow blowing up from underneath.

The mixing for the slot injectors is plotted in Fig. 11 versus aspect ratio. This is the same "mixing metric" described earlier. The percentage of mixed fluid also 
increases with longitudinal aspect ratio. An increase in streamwise vorticity production and spreading apparently leads to better mixing. As aspect ratio increases, a point is reached after which the measured mixing appears to approach a limit. A point is also reached, in this same range of aspect ratio, after which injected fluid is no longer completely cleared from the duct floor (refer to Fig. 8). As injector aspect ratio increases, the ratio of viscous surface area to fluid volume increases (cross-sectional area being held constant). This also causes the boundary layer within the injector to encompass an increasingly large proportion of the injector orifice area. Eventually, the viscous effects of increasing this surface area ratio would become more detrimental than the benefits of increasing the aspect ratio.

Nonetheless, the longitudinal slot clearly provides greater penetration, spreading and mixing than the primary geometries. However, for combustor application, in which compactness is crucial, a longitudinal slot injector may not be practical.

\section{Effect of Injector Inflow Conditions}

The previous results assumed a fixed, constant massflow and flow state for the injector inflow boundary. As explained earlier, it was felt that having a constant injector-to-mainstream massflow ratio would ensure a "fair" comparison of the mixing characteristics of each injector. However, this boundary condition is not necessarily the most realistic.

Thus, all cases were recomputed with constant stagnation conditions imposed at the injector inflow plane. The stagnation pressure and temperature correspond to those of the frozen boundary inflow cases. This variation allowed for the development of the effective discharge coefficient of each case. The discharge coefficients are displayed in Table 2. The circular, diamond, and square injector cases all have very similar discharge coefficients and there is no indication of any one trending toward particularly greater or lesser values. Nonetheless, all three of these injectors produce a considerably larger discharge coefficient than the latitudinal slot injector. As for the rectangular slot injectors, a clear trend is present. There is a direct relationship between discharge coefficient and aspect ratio, though the discharge appears to approach a maximum at the case with largest aspect ratio (8:1). This maximum discharge phenomenon is, no doubt, caused by the increase in viscous effects associated with increasing the ratio of injector surface area to fluid volume, which occurs as a rectangle's aspect ratio increases (as discussed earlier).

\section{Induced Wall Force Study}

The data from this study has been analyzed with a primary focus on mixing applications, since mixing drives combustion and perhaps noise reduction. However, thrust-vectoring of low speed supersonic flows is an application of great interest. An integrated non-dimensional vertical wall force was computed for each injector case (shown in Table 3). This wall force was computed for the 20-inch long section of the duct floor that contains the injector orifice.

The whole duct floor would have been used in the computation, but a difficulty with one of the boundary conditions arose in the solutions. In Fig. 12, a Mach contour plot is shown of the diamond injector case. An expansion wave is generated on the back lip of the injector orifice. This expansion wave propagates itself through the solution and then reflects off of the boundary at the duct ceiling. When the wave reflects off of the ceiling boundary condition, it propagates itself back into the downstream region of the solution and corrupts the pressure data computed on the floor of the duct downstream of $x=40$ in. Consequently, only the floor region between $x=20$ and $x=40$ in. was used for wall force calculation.

The circle, diamond, and square injectors generate very similar wall forces, considerably greater than that of the latitudinal slot. As for the rectangular injectors, the induced wall force seems to increase with aspect ratio and approach something of a limit near the largest aspect ratio of $8: 1$. It is possible that this phenomenon is simply related to the increase in injector mass flow from the longer aspect ratio rectangular slot.

\section{Grid Convergence Study}

For all the cases in this study, grid independent results could not be obtained without an excessively large grid. Consequently, the data acquired is primarily of qualitative value. As described earlier, coarse, medium, and fine grid solutions were obtained for each case. Whereas accurate quantities could not be computed, comparisons were made based on all three grid levels to ensure the constancy of the observed trends. The trends observed in this study-mixing behavior, induced wall forces, and discharge coefficients-are all consistent at all grid resolutions. Both medium and fine grid calculations of discharge coefficient, lift coefficient, and mixing, for all cases, can be found in Tables 2, 3, and 4, respectively. For future study, it may be possible to apply an adaptive grid strategy to obtain grid independent results without excessive computational cost. 


\section{SUMMARY}

The circular, diamond, and square injectors provide deeper injected fluid penetration than does the wide slot injector. This appears to be due mainly to the lifting effects of the increased streamwise vorticity these geometries generate. Fluid injected through the diamond injector penetrates more rapidly than that through the circular and square injectors and is more thoroughly cleared from the duct floor; this is consistent with the findings of others for transverse injection through diamond injectors at similar pressure ratios. Though the diamond injector generates more rapid penetration, it cannot be determined, from this study, whether or not it produces better mixing.

For rectangular injectors, the penetration depth and measured mixing increase with aspect ratio (L/W). Again, this is largely due to a sustained generation of streamwise vorticity over a relatively long streamwise length. This improved vorticity production is likely attributed to a buffering effect, in which the aft portion of the injected flow is shielded from the mainstream by the streamwise vortices, which originate along the forward portion of the injector. The measured discharge coefficient and induced wall force also increase with aspect ratio, though the increase in measured wall force may simply be a function of increased discharge.

\section{REFERENCES}

1. Tomioka, S., et al., "Sonic Injection from Diamond-Shaped Orifices into a Supersonic Crossflow,” J. of Propulsion and Power, Vol. 19, No. 1, Jan.-Feb. 2003.

2. Santiago, J. and Dutton, J., "Crossflow Vortices of a Jet Injected into a Supersonic Crossflow," AIAA Journal, Vol. 35, No. 5, 1997, pp. 915-917.

3. Ben-Yakar, A., Kamel, M., Morris, C., and Hanson, R.K., "Experimental Investigation of $\mathrm{H}_{2}$ Transverse Jet Combustion in Hypervelocity Flows," AIAA, 1997.

4. Bush, R.H., "A Three Dimensional Zonal Navier Stokes Code for Subsonic Through Hypersonic Propulsion Flowfields," AIAA-882830, July 1988.

5. "NPARC User's Guide: Version 3.0," The NPARC Alliance, Sept. 1996.

6. Mentor, F.R., "Zonal Two Equation k-omega Turbulence Models for Aerodynamic Flows," AIAA-93-2906, 1993.

7. Barber, M.J., Schetz, J.A., and Roe, L.A., "Normal, Sonic Helium Injection through a Wedge-Shaped Orifice into Supersonic Flow," Journal of Propulsion and Power, Vol. 13, No. 2, MarchApril 1997, pp. 257-263.

Table 1: Summary of freestream and injector flow conditions

\begin{tabular}{|l|c|c|c|}
\hline & $\begin{array}{c}\text { Freestream } \\
\text { (all runs) }\end{array}$ & $\begin{array}{c}\text { Fixed static injection } \\
\text { (1st set) }\end{array}$ & $\begin{array}{c}\text { Fixed stagnation injection } \\
\text { (2nd set) }\end{array}$ \\
\hline $\mathrm{M}$ & 1.2 & 0.3 & -- \\
\hline $\mathrm{P}(\mathrm{psi})$ & 14.7 & 29.4 & 31.3 \\
\hline $\mathrm{T}\left({ }^{\circ} \mathrm{R}\right)$ & 530.0 & 670.6 & 682.6 \\
\hline
\end{tabular}

Table 2: Discharge coefficients

\begin{tabular}{|l|c|c|}
\hline \multicolumn{1}{|c|}{ Configuration } & Medium grid & Fine grid \\
\hline Circle & 0.460 & 0.528 \\
\hline Diamond & 0.488 & 0.524 \\
\hline Latitudinal slot & 0.335 & 0.287 \\
\hline Rectangle 1:3 & 0.333 & 0.333 \\
\hline Rectangle 1:2 & 0.418 & 0.443 \\
\hline Rectangle 1:1 (square) & 0.464 & 0.501 \\
\hline Rectangle 2:1 & 0.517 & 0.553 \\
\hline Rectangle 3:1 & 0.568 & 0.636 \\
\hline Rectangle 5:1 & 0.608 & 0.712 \\
\hline Rectangle 8:1 & 0.605 & 0.719 \\
\hline
\end{tabular}


Table 3: Lift coefficients

\begin{tabular}{|l|c|c|}
\hline \multicolumn{1}{|c|}{ Configuration } & Medium grid & Fine grid \\
\hline No injection & 0 & 0 \\
\hline Circle & -0.1194 & -0.1197 \\
\hline Diamond & -0.1213 & -0.1251 \\
\hline Latitudinal slot & -0.09492 & -0.07090 \\
\hline Rectangle 1:3 & -0.07529 & -0.07364 \\
\hline Rectangle 1:2 & -0.09975 & -0.1025 \\
\hline Rectangle 1:1 (square) & -0.1244 & -0.1179 \\
\hline Rectangle 2:1 & -0.1377 & -0.1344 \\
\hline Rectangle 3:1 & -0.1479 & -0.1563 \\
\hline Rectangle 5:1 & -0.1660 & -0.1692 \\
\hline Rectangle 8:1 & -0.1527 & -0.1744 \\
\hline
\end{tabular}

Table 4: Mixed flow percentage

\begin{tabular}{|l|c|c|}
\hline \multicolumn{1}{|c|}{ Configuration } & Medium grid & Fine grid \\
\hline Circle & 17.670 & 13.378 \\
\hline Diamond & 17.032 & 13.624 \\
\hline Latitudinal slot & 11.814 & 8.822 \\
\hline Rectangle 1:3 & 14.946 & 12.184 \\
\hline Rectangle 1:2 & 15.873 & 13.346 \\
\hline Rectangle 1:1 (square) & 17.193 & 14.341 \\
\hline Rectangle 2:1 & 19.177 & 15.285 \\
\hline Rectangle 3:1 & 20.260 & 16.246 \\
\hline Rectangle 5:1 & 22.439 & 18.649 \\
\hline Rectangle 8:1 & 27.839 & 20.539 \\
\hline
\end{tabular}

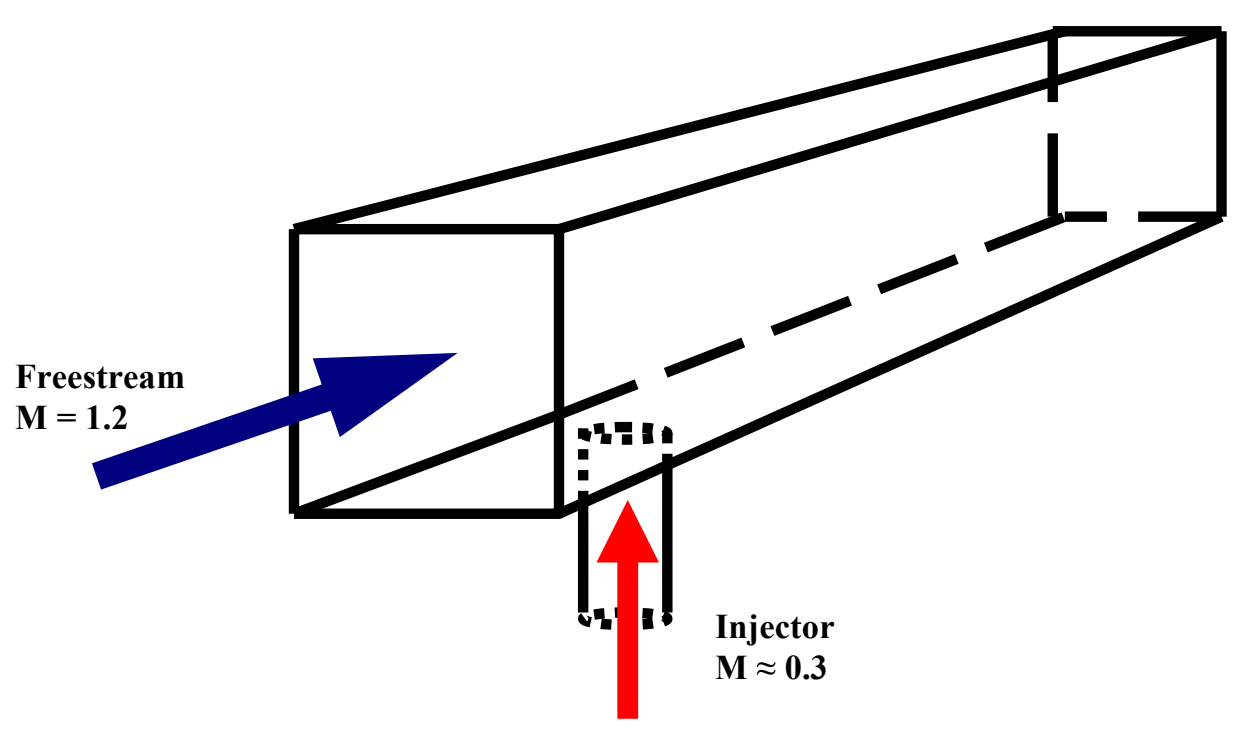

Figure 1: Supersonic duct with transverse injector 


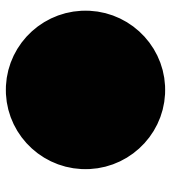

Circle

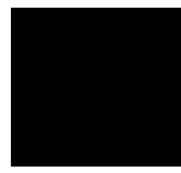

Square

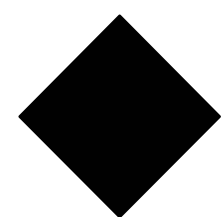

Diamond
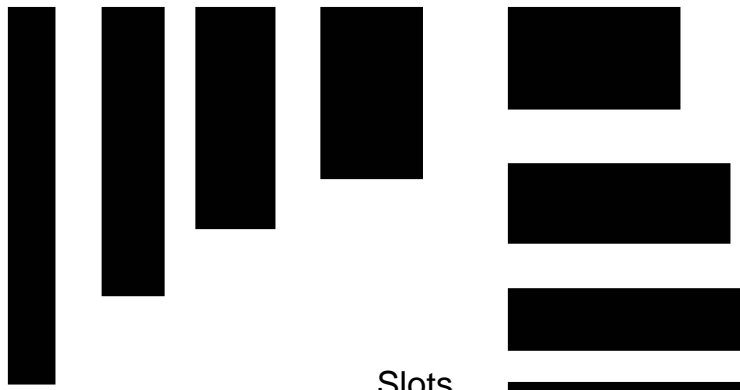

Slots

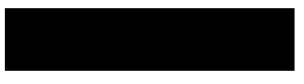

Figure 2: Injector orifice geometries

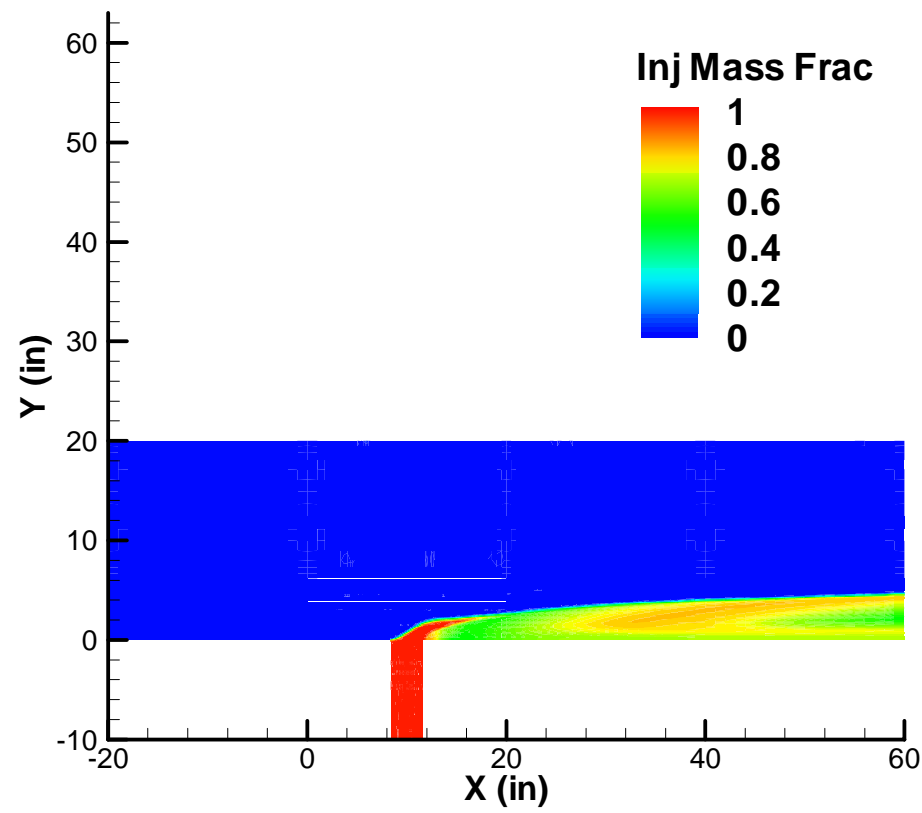

Figure 3: Mass fraction contour plot for duct with circular injector 


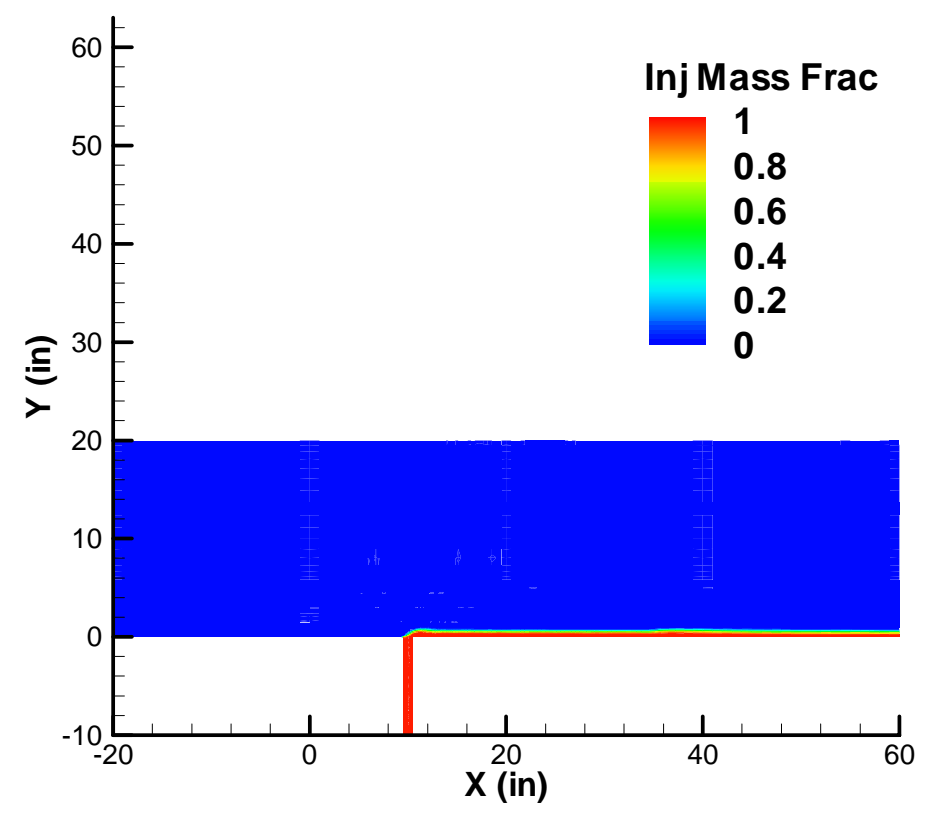

Figure 4: Mass fraction contour plot for duct with 1:8 slot injector
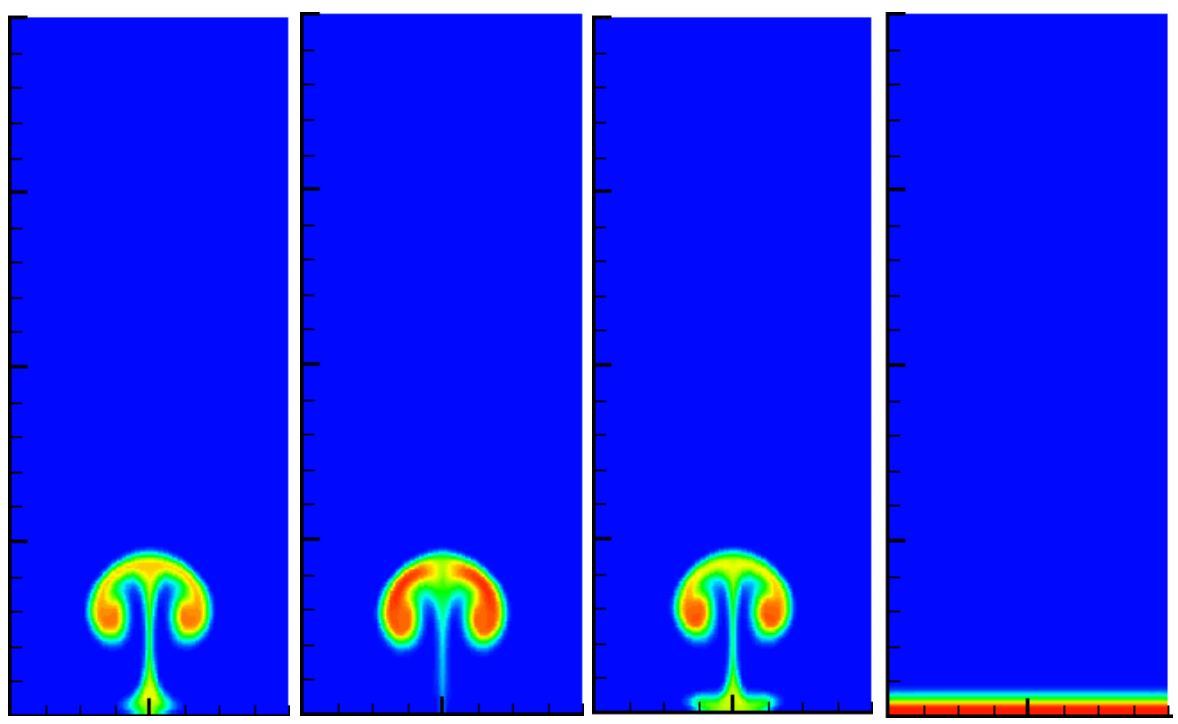

Inj Mass Frac

1

0.8

0.6

0.4

0.2

0

Figure 5: Mass fraction contour plots for injector ducts 50 in. downstream of injector 


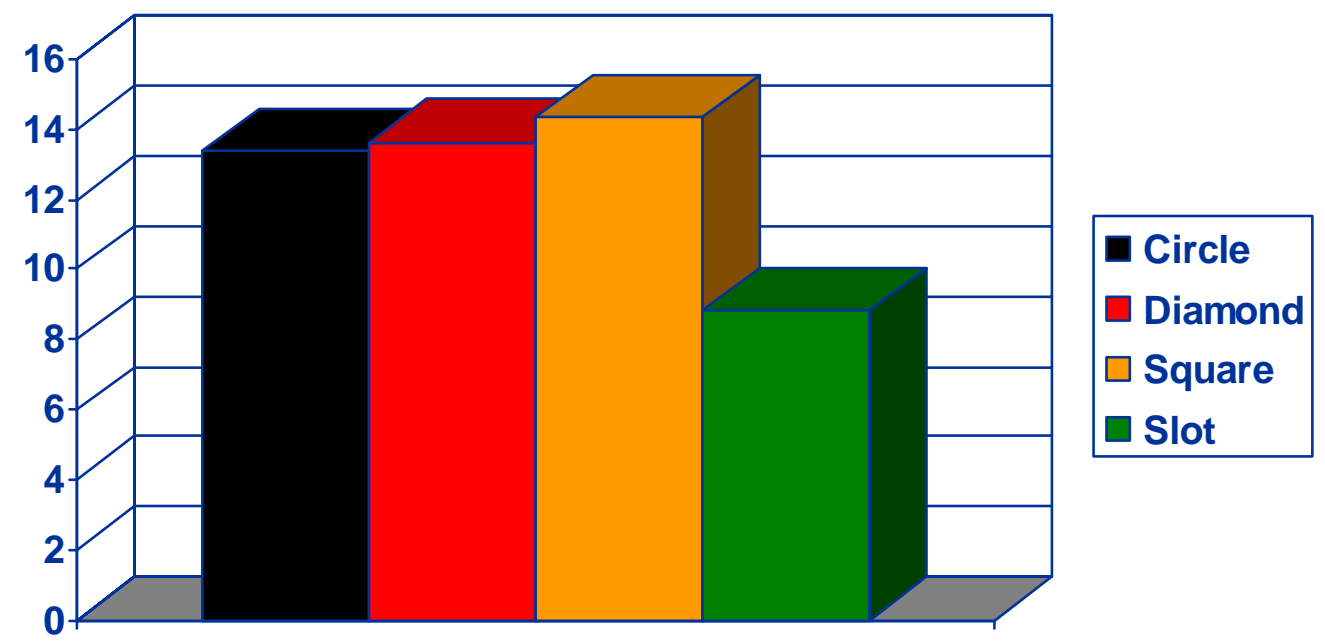

Figure 6: Mixed flow percentage at 1 percent minimum injectant mass fraction tolerance

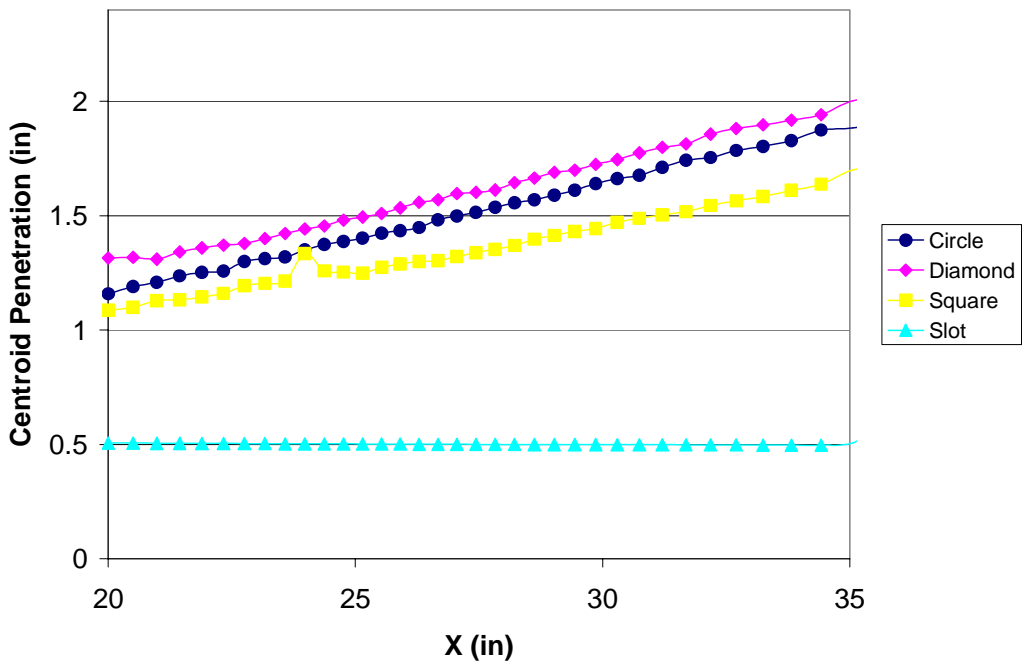

Figure 7: Injectant centroid penetration 


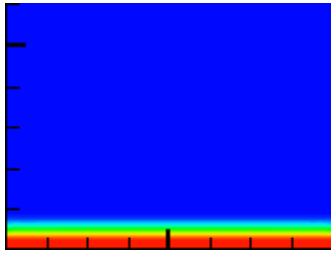

$\mathrm{L} / \mathrm{W}=0.125$

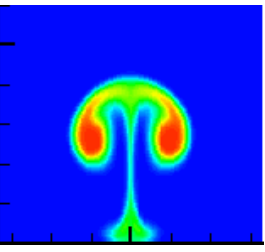

$\mathrm{L} / \mathrm{W}=1.7$
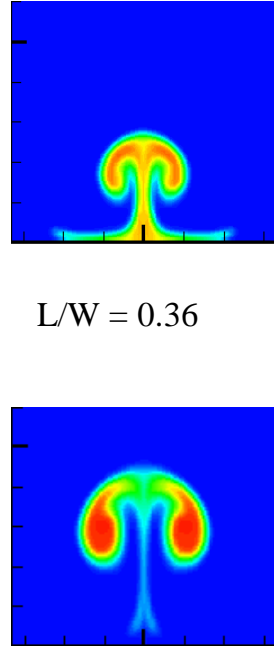

$\mathrm{L} / \mathrm{W}=0.36$

$\mathrm{L} / \mathrm{W}=2.8$

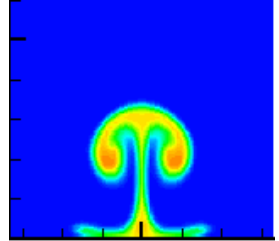

$\mathrm{L} / \mathrm{W}=0.59$

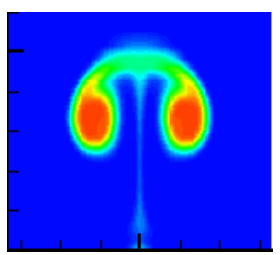

$\mathrm{L} / \mathrm{W}=4.8$

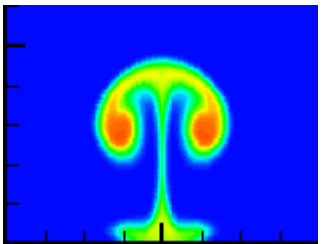

$\mathrm{L} / \mathrm{W}=1$

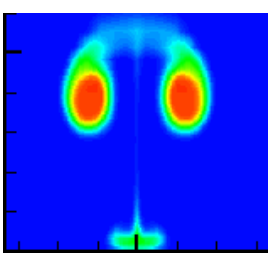

Inj Mass Frac

1
0.8

0.8

0.4

0.2

Figure 8: Injectant mass fraction contours of rectangular injector ducts 50 in. downstream of injector

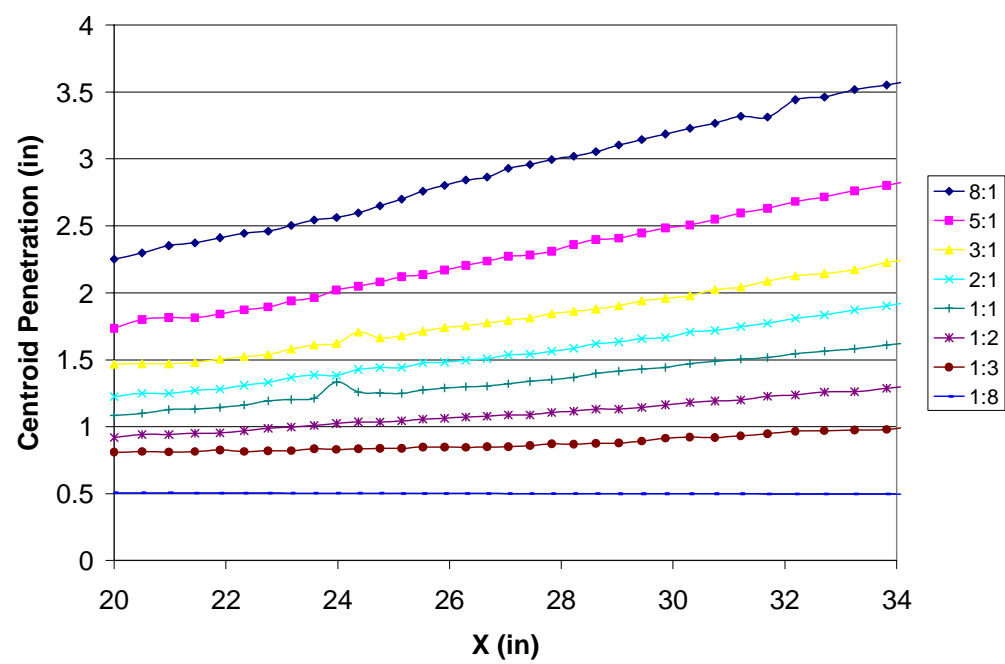

Figure 9: Centroid penetration (rectangular injectors) 


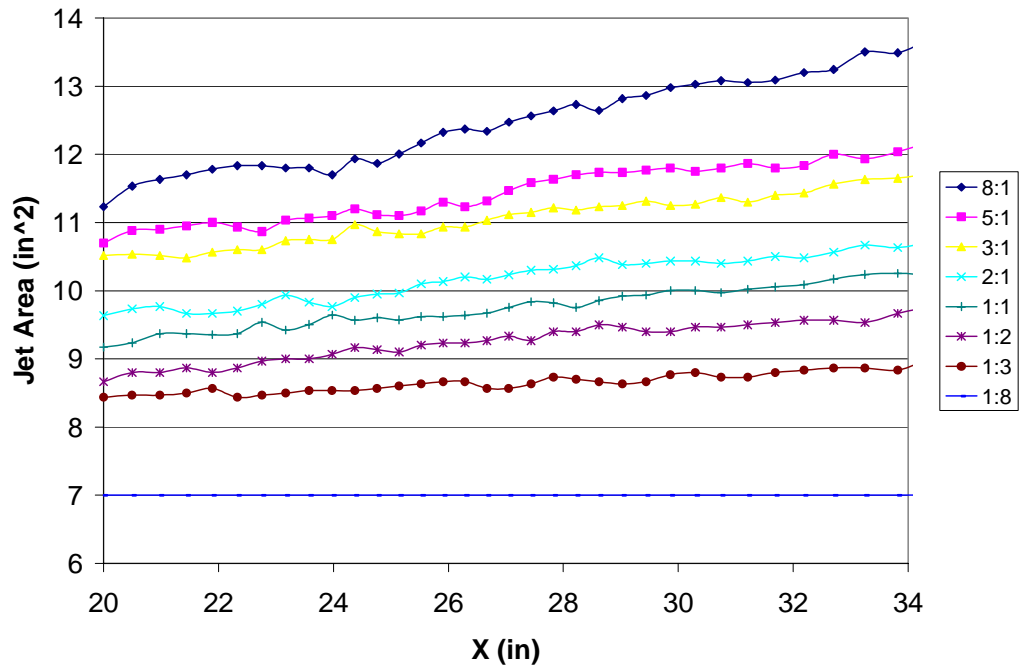

Figure 10: Jet area (rectangular injectors)

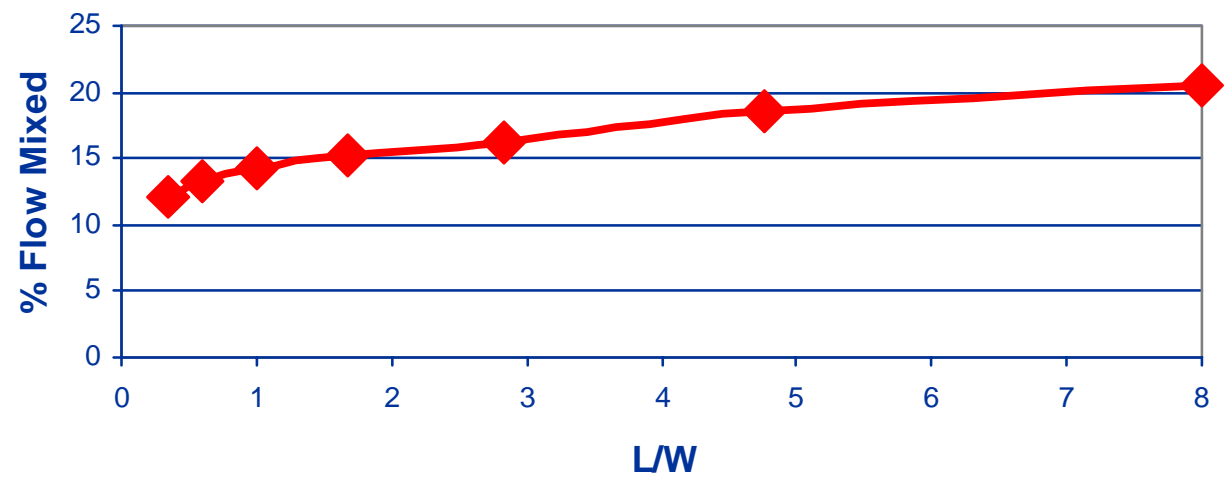

Figure 11: Percent flow mixed versus aspect ratio for rectangular injectors 


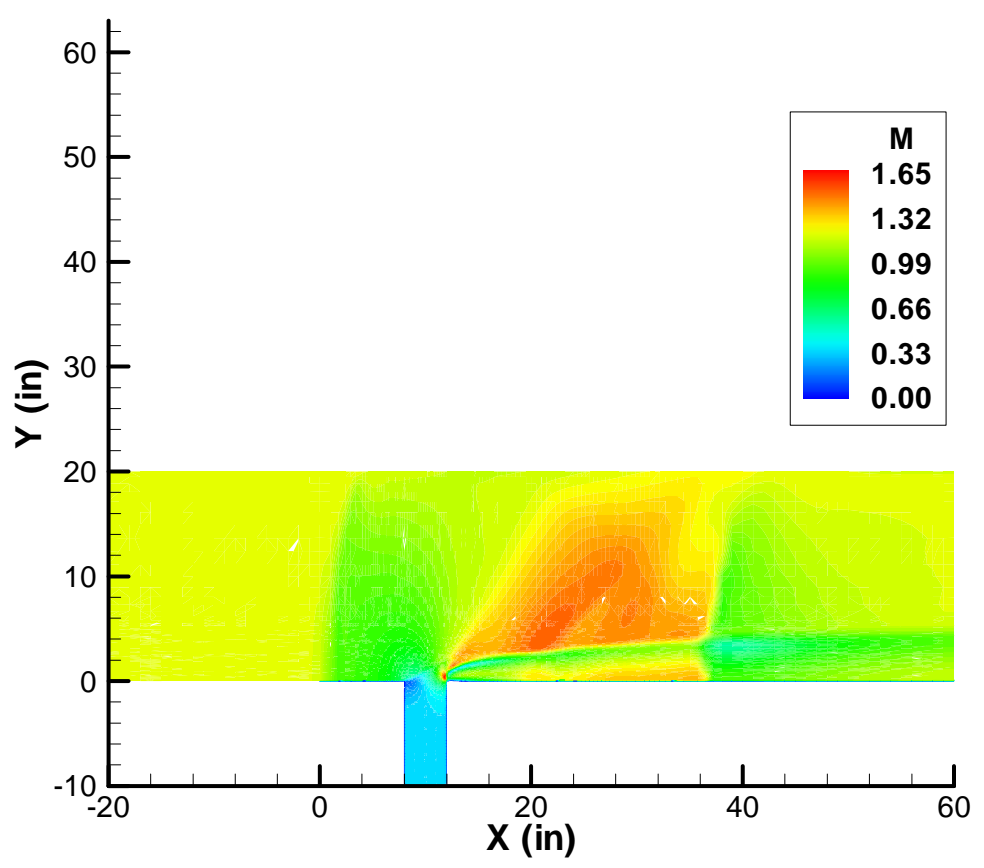

Figure 12: Mach contour plot 

Public reporting burden for this collection of information is estimated to average 1 hour per response, including the time for reviewing instructions, searching existing data sources, gathering and maintaining the data needed, and completing and reviewing the collection of information. Send comments regarding this burden estimate or any other aspect of this collection of information, including suggestions for reducing this burden, to Washington Headquarters Services, Directorate for Information Operations and Reports, 1215 Jefferson Davis Highway, Suite 1204, Arlington, VA 22202-4302, and to the Office of Management and Budget, Paperwork Reduction Project (0704-0188), Washington, DC 20503.

\begin{tabular}{|l|l|l}
\hline 1. AGENCY USE ONLY (Leave blank) & $\begin{array}{c}\text { 2. REPORT DATE } \\
\text { December } 2003\end{array}$ & $\begin{array}{r}\text { 3. REPORT TYPE AND DATES COVERED } \\
\text { Technical Memorandum }\end{array}$ \\
\hline
\end{tabular}

\section{TITLE AND SUBTITLE}

Computation of Transverse Injection Into Supersonic Crossflow With Various Injector Orifice Geometries

\section{AUTHOR(S)}

Lancert E. Foster and William A. Engblom

\section{FUNDING NUMBERS}

WBS-22-708-92-24

\section{PERFORMING ORGANIZATION NAME(S) AND ADDRESS(ES)}

National Aeronautics and Space Administration

John H. Glenn Research Center at Lewis Field

Cleveland, Ohio 44135-3191

8. PERFORMING ORGANIZATION REPORT NUMBER

E-14291

\section{SPONSORING/MONITORING AGENCY NAME(S) AND ADDRESS(ES)}

National Aeronautics and Space Administration

Washington, DC 20546-0001

10. SPONSORING/MONITORING AGENCY REPORT NUMBER

NASA TM-2003-212878

AIAA-2004-1199

\section{SUPPLEMENTARY NOTES}

Prepared for the 42nd Aerospace Sciences Meeting and Exhibit sponsored by the American Institute of Aeronautics and Astronautics, Reno, Nevada, January 5-8, 2004. Lancert E. Foster, NASA Glenn Research Center; and William A. Engblom, The Aerospace Corporation, Cleveland, Ohio 44135. Responsible person, Lancert E. Foster, organization code 5860, 216-433-6659.

12a. DISTRIBUTION/AVAILABILITY STATEMENT 12b. DISTRIBUTION CODE

Unclassified - Unlimited

Subject Category: 07

Distribution: Nonstandard

Available electronically at http://gltrs.grc.nasa.gov

This publication is available from the NASA Center for AeroSpace Information, 301-621-0390.

13. ABSTRACT (Maximum 200 words)

Computational results are presented for the performance and flow behavior of various injector geometries employed in transverse injection into a non-reacting Mach 1.2 flow. 3-D Reynolds-Averaged Navier Stokes (RANS) results are obtained for the various injector geometries using the Wind code with the Mentor's Shear Stress Transport turbulence model in both single and multi-species modes. Computed results for the injector mixing, penetration, and induced wall forces are presented. In the case of rectangular injectors, those longer in the direction of the freestream flow are predicted to generate the most mixing and penetration of the injector flow into the primary stream. These injectors are also predicted to provide the largest discharge coefficients and induced wall forces. Minor performance differences are indicated among diamond, circle, and square orifices. Grid sensitivity study results are presented which indicate consistent qualitative trends in the injector performance comparisons with increasing grid fineness.

\section{SUBJECT TERMS}

Transverse injection; Injector

\begin{tabular}{|c|c|}
\hline $\begin{array}{c}\text { 17. SECURITY CLASSIFICATION } \\
\text { OF REPORT } \\
\text { Unclassified }\end{array}$ & $\begin{array}{c}\text { 18. SECURITY CLASSIFICATION } \\
\text { OF THIS PAGE } \\
\text { Unclassified }\end{array}$ \\
\hline
\end{tabular}

\section{SECURITY CLASSIFICATION OF ABSTRACT \\ Unclassified}

15. NUMBER OF PAGES

18

16. PRICE CODE

\section{LIMITATION OF ABSTRACT}

